\title{
From Normal Cells to Malignancy: Distinct Role of Pro-inflammatory Factors and Cellular Redox Mechanisms
}

\author{
Rajendra K Singh $^{1,2 *}$, Akulapalli Sudhakar ${ }^{3,4,5}$ and Bal L Lokeshwar ${ }^{1,2}$
}

${ }^{1}$ Department of Urology, Miller School of Medicine, University of Miami, Miami, FL 33136, USA

${ }^{2}$ Veterans Administration Miami Hospital, Miami, Florida, USA

${ }^{3}$ Cell Signaling, Retinal and Tumor Angiogenesis Laboratory, Department of Genetics, Boys Town National Research Hospital, Omaha, NE 68131, USA

${ }^{4}$ Department of Biomedical Sciences, Creighton University School of Medicine, Omaha, NE, 68178, USA

${ }^{5}$ Department of Biochemistry and Molecular Biology, University of Nebraska Medical Center, Omaha, NE, 68198, USA

\begin{abstract}
The genesis of many solid cancers is a complex, multistep process that includes cellular neoplastic transformation, resistance to apoptosis, loss of control of cell cycle, angiogenesis and acquisition of invasive properties. Among a number of factors, the simultaneous existence of chronic inflammatory mechanism and downregulation of antioxidant defense mechanism of cells are emerging as major causes of neoplastic transformation and the progression of many solid cancers. The longer the inflammation persists, higher the risk of developing many ages related malignancies such as organs of colon, stomach and prostate the Concurrent occurrence of these processes that may affect DNA mutations in cells by excessive generation of free radicals, Reactive Oxygen Species (ROS) and other active intermediates that exceed the limit of the cells ability to neutralize it. Chronic inflammatory conditions may activate a variety of pro-tumorigenic activities, such as stimulation of proliferative pathway, chemotactic activity, increased invasive potential of cells and angiogenesis. However, many of the antioxidants or cellular redox molecules play a crucial role in maintaining cellular homeostasis and response to oxidative damage but down-regulation of some of the cellular molecules of this process may lead to malignant transformation. We provide an overview of the possible mechanism(s) of interaction of pro-inflammatory factors in down-regulating the antioxidant and cellular redox mechanism(s) making cells susceptible to carcinogenesis. The elucidation of specific effects and interactions of these factors may provide the opportunity for the identification of new target molecules at the early stage of human malignancies.
\end{abstract}

Keywords: Inflammation; Antioxidant; Cellular redox; Nuclear factor-kappaB; Malignant transformation; Chemokines and chemokinereceptors

\section{Introduction}

Many human organs can take several years to turn malignant and have many causes. Cancer is more common in many industrialized nations, but there has been a growth in cancer rates in developing countries too, particularly as these nations adopt the diet and lifestyle habits of industrialized countries [1]. Over one million people in the United States get cancer every year. Anyone can get cancer at any age; however, about 80 percent of all cancers occur in people over the age of fifty-five and above [2]. The four most common cancers that account for over 50 percent of total cancer cases in the United States are: lung, colon/rectum, breast and prostate cancers [2].

Several factors both inside and outside of the body may contribute to the development of many cancer types. Many of these solid cancers were initially thought to be genetic diseases but research in the last decade has proven that cancer is predominantly an environmental disease with $80-90 \%$ of cases due to environmental and lifestyle factors, where as only $5-10 \%$ are caused by genetics alterations [3]. Some common environmental factors that lead to cancer that includes: tobacco (25-30\%) [4], diet and obesity (30-35\%) [5], infections, radiation and direct exposure to other environmental pollutants (1520\%) [6-8].

The progression human malignancies involve multistep processes and are accomplished by the combined effects of alterations of many physiological and pathological signaling processes [9]. Among a number of different biochemical events, the existence of chronic inflammation persistence in development of cancer has been gaining much attention in the case of stomach, colon as well as prostate cancers [10,11]. Prolonged exposure to environmental factors generates excessive expression of pro-inflammatory genes that leads to alteration of the expression and function of oncogenes and/or tumor suppressor genes either due to epigenetic mutations or loss of expression of antioxidant molecules [12-16]. Constitutive activation of some common inflammatory mediators including chemokines, IL-8, IL-6, reactive oxygen species nitrogen species (RONS), cyclooxygenase-2 (COX-2) and nuclear factor (NF)- $\kappa B$ are known to maintain cellular conditions favorable for malignant progression [1719]. In many established solid cancers, the tumor microenvironment is well maintained by these inflammatory factors for tumor cell proliferation, survival and metastasis. Much of the published literature has highlighted the important role of inflammatory molecules in progression of these malignancies, whereas present literature related to the cellular redox sensitive mechanism in malignant transformation are not clearly explained yet. Although present literature has shown that down regulation of some of these factors in a number of solid malignancies and supplementation of chemo-preventive agents or antioxidant agents reduced the tumor burden [20,21]. In this review, we

*Corresponding author: Rajendra K Singh, Ph.D, Department of Urology, Miller School of Medicine, University of Miami, Miami, FL, 33136, USA, Tel: (305) 2431017; Fax: (305) 243-9724; E-mail: singhrkbio@rediffmail.com

Received January 05, 2010; Accepted March 08, 2011; Published March 12 2011

Citation: Singh RK, Sudhakar A, Lokeshwar BL (2011) From Normal Cells to Malignancy: Distinct Role of Pro-inflammatory Factors and Cellular Redox Mechanisms. J Cancer Sci Ther 3: 070-075. doi:10.4172/1948-5956.1000061

Copyright: ( 2011 Singh RK, et al. This is an open-access article distributed under the terms of the Creative Commons Attribution License, which permits unrestricted use, distribution, and reproduction in any medium, provided the original author and source are credited. 
further provide an uncovered connection of the specific inflammatory and oxidant damage mechanism in recent development role of microRNAs in malignant transformation. The elucidation of specific effects and interactions of these various factors may provide the opportunity to identify new target molecules that leads to improve a diagnosis and treatment of many types of cancers.

\section{Role of ROS in carcinogenesis}

Reactive oxygen species (ROS) and reactive nitrogen species (collectively RONS) are highly reactive radicals which play an important role in the innate immune system [22]. The main feature of many cancer cells is a persistent to the oxidative state that leads to activation of intrinsic oxidative stress signaling [22]. Cancer cells have higher levels of reactive oxygen species than normal cells, and ROS are responsible for the maintenance of the many age related cancer phenotypes such as prostate and colon cancers [23-24]. Persistent ROS stress may induce adaptive stress responses, enabling cancer cells to survive with high levels of ROS and maintain cellular viability [25]. Although precise cancer cell survival mechanism is not yet known and how ROS acts as a "Double-Edged Sword". Since the innate immune system comprises the cells to defend the host from infection or damage, in a non-specific manner. This means, cells of the innate system recognize and respond to host in a generic way, but unlike the adaptive immune system, it does not confer long-lasting or protective immunity to the infection [26]. Innate immune systems provide immediate defense, and are found in all classes of plant and animal life. In response to a stimulus, for example phagocytic cells release RONS and nonphagocytic cells produces RONS by pro-inflammatory cytokines and chemokines such as IFN $\gamma$, TNFa and IL1 $\beta$ [26]. Such induction occurs at the transcriptional level through the activation of many transcription factors. The cytotoxic effects of NO (nitric oxide) are partly due to the production of peroxynitrite, a reactive oxidant formed by the rapid reaction of NO and superoxide [27]. The production of RONS by phagocytes induces cell death by phagocytic destruction and apoptosis, for instance oxidative stress induces p53 protein accumulation in prostate cancer cells directing them to die by apoptosis $[29,30]$. On the other hand, up-regulation of RONS, increased oxidative stress that may contribute to carcinogenesis [30]. RONS expression and its activity are up-regulated in several experimental models [31]. In fact, RNOS activation is increased and its expression correlates with dysregulation of cellular redox potential and the degree of malignancy [32].

Increased expression of RNOS was more pronounced in highgrade tumors in both the tumor vasculature and in peri-tumoral areas $[33,34]$. RNOS activity up-regulated in prostate and colon cancers are well known, and lead to DNA damage and aberrant DNA crosslinking, thereby causing genomic instability such as inhibition of p53 protein transcriptional activity $[35,36]$. It is therefore conceivable that with prolonged exposure of cells to higher concentrations of RONS leads to chronic inflammatory process, and oncogenic progression in age related malignancies [36]. For example, epidermal growth factor receptor (EGFR), Akt and ERK activation are well known regulator of ROS-dependent cell proliferation and anti-apoptotic pathways $[37,38]$. RONS can post-translationally modify and inactivate the retinoblastomal tumor suppressor protein and thus lead to support tumor cell proliferation [39]. Furthermore, elevated RONS can increase angiogenesis and transcriptional activation of oncogenes [40]. Noticeably, a wide range of in-vitro and in-vivo models showed that RNOS signaling can induce COX-2 and MAPK signaling, which itself is a potential link between inflammation and cancer [41]. A possible mechanism mediated by environmental factors in oncogenic response is shown in Figure 1.

\section{Molecular link of Inflammation and cancer related risk factors}

In the last several years efforts have been made to shed new light on molecular and cellular signaling circuits linking inflammation and cancer [42]. Two major pathways have been well identified. (A) The Intrinsic pathway, in which genetic events cause neoplasia initiate the expression of inflammation-related molecules which would guide the construction of an inflammatory microenvironment. (B) In the extrinsic pathway inflammatory conditions facilitate cancer development [43]. The triggers of chronic inflammation increase cancer risk or progression include infections (e.g. H. pilori for gastric cancer and mucosal lymphoma; papilloma virus and hepatitis viruses for cervical and liver carcinoma, respectively), autoimmune diseases (e.g. inflammatory bowel disease for colon cancer) and inflammatory conditions of uncertain origins (e.g. prostatitis and prostatic intraepithelial precursor for prostate cancer) [44-47]. In both the above pathways, orchestrators of many molecules including, transcription factors and several pro-inflammatory factors such as IL-8, IL-6 and SDF-1, cause cancer related inflammation and tumor progression [4852].

Contributions of potential genetic and environmental risk factors for the onset of cancer are identified at the molecular level. Moreover the distribution and rise prevention of the disease have been identified in several animal studies and did not give a final outcome of the connection of these mechanism. Some genome-wide studies identified the genes that were involved in the common process of inflammatory responses. However they do not correlate their molecular links in malignant transformation [53]. Examining the impact of inflammation and cancer related risk factot in malignant transformation remains a challenge for scientists due to the lack of appropriate animal models. A possible signaling mechanism in activation of pro-inflammatory mediators in development of cancer is described in Figure 2.

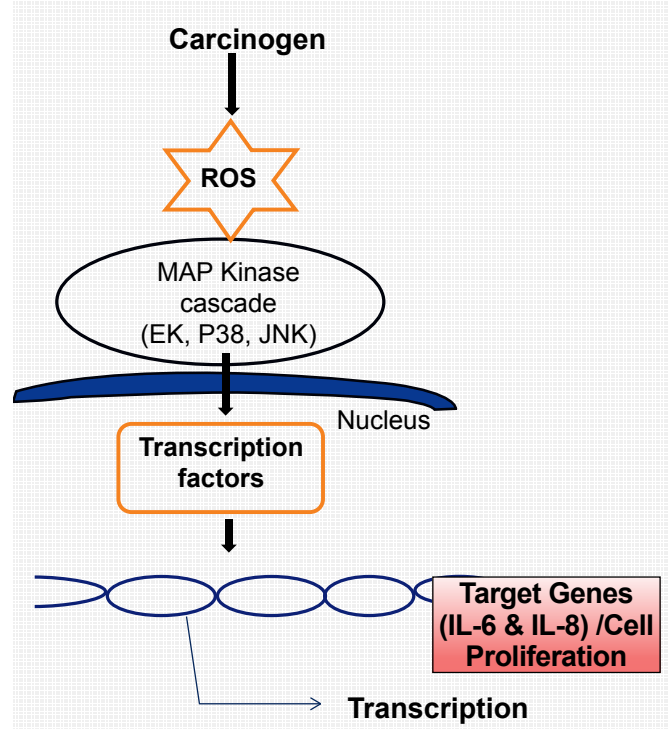

Figure 1: A possible interaction between environmental factors and ROS in activation of proinflammatory factors in carcinogenesis. 
The link between pro-inflammatory pathway and cellular redox balance: New dilemma of nuclear factor-kB (NF-kb) pathway in this mechanism

The epithelium is a major target not only as an inert barrier, but it is also a major participant in signaling mechanisms during development and patho-physiological conditions [54]. Therefore, any damage caused to the epithelium can adversely affect its normal physiology and signaling processes. The major functions of the epithelium include: (i) it is a dynamic physiological barrier to diffusion and osmotic processes; (ii) it provides an integral metabolic function by synthesizing and degrading chemical components either endogenously produced or exogenously introduced; and (iii) it possesses a secretory property to produce chemokines, hormones, growth factors and enzymes $[55,56]$. This underlines the significance of a physiologically competent of the epithelium, because metabolic failure or noxious damage by many external factors would lead to abnormalities in normal development and disease progression $[55,56]$. The transition mechanism from the epithelium to other compartments are controlled by redox-sensitive transcription factors including activation of apoptotic signaling and pro-inflammatory cytokines and chemokines $[55,56]$.

$\mathrm{Rel} / \mathrm{NF}-\mathrm{kB}$ is a family of dimeric transcription factors that control the expression of numerous genes involved in the inflammatory process and other physiological responses of cells [57]. Many genes including TNFa, IL-1 $\beta$, IL-6, IL-8, IL-12 cell adhesion molecules (vascular cell adhesion molecule-1 and intercellular cell adhesion molecule-1), iNOS, and COX-2 have been known to be regulated via the NF- $\kappa b$ transcription factor $[58,59]$. Activation of many of these genes is involved in cell growth, differentiation, regulation of apoptosis, chemotaxis and metastasis progression in prostate and other solid cancers (Figure 2) $[60,61]$. These factors become activated by exposure to pro-inflammatory stimuli or activation of inflammatory responsive gene element that controls cellular redox balance mechanism [62,63], such as activation of oxygen-evoked sensitive HIF-1 $\alpha$ and NF- $\kappa B$. These two factors closely coupled with intracellular redox state or redox equilibrium and responsive to expression and trans-activation of many genes. So the differential regulation of HIF-1 $\alpha$ and NF- $\kappa B$ by oxygen-sensitive and redox-dependent pathways may play a role in inflammation related diseases [64] (Figure 3).

Concerning prostate cancer, present literature provides strong evidence confirming that HIF-1 $\alpha$ and NF- $\kappa$ B factors are playing prominent role in proliferation and survival of tumor cells $[62,63]$. It was further reported that in many studies NF- $\kappa \mathrm{B}$ activation in response to chemotherapeutic agents and radiation somewhat protected many tumor cells in-vitro. We recently found the presence of constitutive expression of IL-8 in prostate cancer cells enhanced the activation of NF- $\mathrm{kB}$ and enhanced the effectiveness of chemo-therapy drugs $[64,65]$.

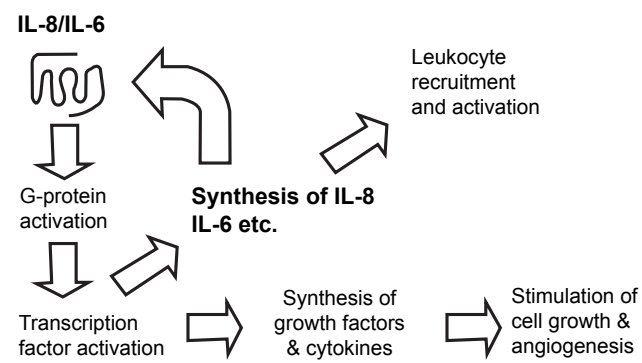

Figure 2: Possible Mechanism of proinflammatory factors mediated carcinogenesis.

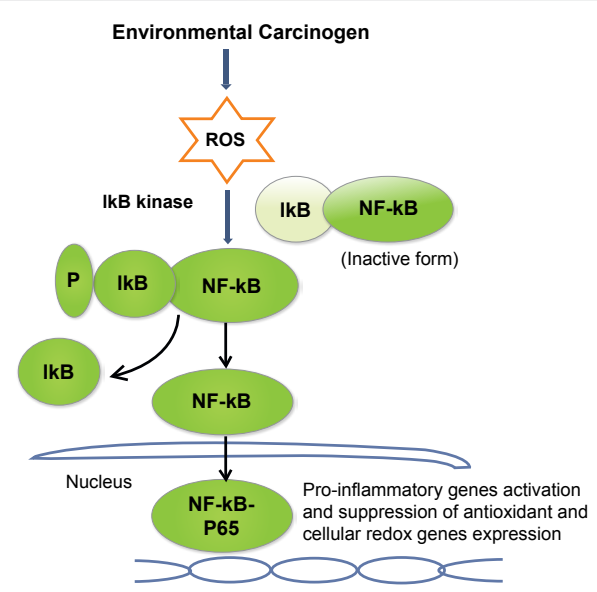

Figure 3: Possible interaction of activation of pro-inflammatory factors in dysregulation of antioxidant and cellular redox mechanism in carcinogenesis (IKB= Nuclear factor Kappa B)

The increased NF- $\kappa \mathrm{B}$ - transcriptional activity reported in many malignancies [51]. However the mechanism of oncogenic response in the activation of that pro-inflammatory factors in de-regulation of antioxidant and cellular redox mechanism in carcinogenesis is not known. Mechanism proposed in Figure 3.

Recently these factors have been shown to control anti-apoptotic proteins $\mathrm{Bcl}-2$ and $\mathrm{Bcl} . \mathrm{xL}$ expressions in prostate cancer. $\mathrm{Bcl}-2$ expression was altered when expression of IL- 8 was down-regulated in prostate cancer cells (PC-3 and DU145) [48]. The down-regulation of IL- 8 by siRNA increases the apoptosis and sensitized the response of cancer cells to chemotherapeutic drugs Docetaxel and Staurosporine [48]. The over-expression of IL-8 is associated through activation of two cognate cell surface receptors CXCR1 and CXCR2 that may be mediated through NF- $\mathrm{kB}$ activation (65). In many experimental models, it has been demonstrated that there is an activation of NF- $\kappa B$ in intestinal and prostate tumor macrophages, where the constitutive production of chemokines, particularly IL-6 and IL-8, are required to drive the proliferation of premalignants intestinal epithelial cells $[48,49]$. IL-6 is also known to exert its proliferatives effect on the many epithelial cells, through the activation of another transcription factor called signal transducer and activators of transcription-3 (STAT3), which further synergizes with NF- $\kappa \mathrm{B}$ to increase the expression of many survival genes responsive to cancer cell survival in the cancer cells [50].

Many factors secreted by monocytes and macrophages contribute to chronic inflammation. Many of the inflammatory gene promoters have specific binding sites for transcriptional modulators, and up-regulation occurs in the setting of synergistic interaction of transcriptional factors, especially during oxidative stress or hypoxia/ anoxia stimulation. IL-8 exerts its function through linkage with three different kind of G-protein-coupled chemokine receptors, CXCR1, CXCR2 that is known to be associated with G-protein signaling and Duffy antigen receptor (DARC). Recently, we have shown that IL-8 also interact with CXCR7 and exert major signaling pathway for cell survival [66]. Thus pro-inflammatory mediators play a significant role in autocrine and paracrine mechanism(s) in response to tissue stress that promotes the development of neoplasia.

Micro RNA as regulatory molecules in inflammation and cancer

MicroRNAs (miRNAs) are recently discovered a class of small, 
evolutionarily conserved RNA molecules, which is known to negatively regulate gene expression at the post-transcriptional level [67]. miRNAs consist of 18 to 25 nucleotides that are modulating gene expression via the RNA interference (RNAi) pathway. RNAi is a post-transcriptional silencing mechanism present in most eukaryotic organisms, in which exposure to double-stranded RNA induces the sequence specific degradation of homologous messenger RNAs (mRNA) [68]. miRNAs act by base-pairing with their target mRNAs through perfect or near perfect complementarily, particularly at the $3^{\prime}$ untranslated regions (UTRs) of the target mRNAs, that leads to their translational repression and/or direct cleavage [69]. Many of microRNAs may play a role in the tumorigenesis and progression of cancer [70].Recently, researchers demonstrated that miR-15a and miR-16-1 expression was inversely correlated to Bcl-2 expression in Chronic Lymphocytic Lymphoma (CLL) and both these miRNAs negatively regulate Bcl-2 at a posttranscriptional level [71]. Furthermore, the Bcl-2 repression by these miRNAs was induced apoptosis in a leukemic cell lines [72,73]. The molecular mechanism(s) played by micro RNA of the inflammatory process is regulated by miRNAs an entirely novel level of regulatory control.

Increased levels of miR-21 have also been found in several chronic inflammatory diseases [74]. Extensive research has explored miRNA involvement in the development and fate of immune cells and in both the innate and adaptive immune responses. Whereas strong evidence links between miRNA expression to signaling pathways and receptors with critical roles in the inflammatory response such as NF- $\kappa B$ and toll-like receptors are reported [74]. The elevated levels of miR-21 were observed in cancer tissues that may be in part responsible for inflammation-associated with colon cancer progression [75]. MiR-21 targets a number of tumor suppressor genes including programmed cell death-4 (PDCD4) and increased miR-21 expression can increase cell proliferation and inhibit apoptosis, stimulates invasion, intravasation and metastasis in colorectal cancers [75]. Inflammatory stimuli can increase the expression of miR-21 and 181b-1 via PTEN and CYLD which are part of the epigenetic switch linking inflammation to cancer [76-77]. The EGFR pathway has also been shown to increase miR-21 expression that regulates anti-apoptotic pathway in lung cancer [78]. Understanding the role of miRNAs in modulation of gene expressions, that leads to sustaine chronic inflammation is important for the development of new therapies for cancer progression.

\section{Conclusions}

We have learned much about the role of inflammation, inflammatory processes and inflammation mediators in the pathogenesis of age related disease cancer. Present evidence suggested that genetic alteration or environmental exposure is linked to prostate, and other site malignancies may be due to early loss of cellular protection to oxidative damage, that participate in the increase of chronic inflammatory responses. The activation of inflammatory mediators including cytokines, chemokines, RONS, COX-2 and NF- $\kappa \mathrm{B}$ can create cellular conditions favorable to malignant transformation due to loss or imbalance of cellular redox and antioxidant signaling. Perturbation of antioxidant or cellular redox mechanisms may be required in order to enhance the tumor associated environment of many cells. Understanding these pathways in animal and other models may enhance potential health benefits of a number of antioxidants or anti-inflammatory agents, and maintenance of the cellular redox status crucial for optimal cellular function.

\section{Acknowledgements}

This work was supported by grant from VA merit Review (VAMC 5312.1 to BLL) and Flight Attendant Medical Research Institute Young Clinical Scientist Award Grant (062558_YCSA to AS), NIH grant (RO1CA143128 to AS) and startup funds of Cell Signaling, Retinal and Tumor Angiogenesis Laboratory at Boys Town National Research Hospital to AS.

\section{References}

1. WHO (2006) Cancer. World Health Organization.

2. Altekruse SF, Kosary CL, Krapcho M, Neyman N, Aminou R, et al. (2010) SEER Cancer Statistics Review, 1975-2007, National Cancer Institute. Bethesda MD, based on November 2009 SEER data submission, posted to the SEER web site.

3. Kinzler KW, Vogelstein B (2002) Introduction - The genetic basis of human cancer (2nd, illustrated, revised ed.). New York: McGraw-Hill, Medical Publications.

4. Kuper H, Boffetta P, Adami HO (2002) Tobacco use and cancer causation: association by tumour type. J intern med 252: 206-224.

5. Danaei G, Vander Hoorn S, Lopez AD, Murray CJ, Ezzati M (2005) Causes of cancer in the world: comparative risk assessment of nine behavioural and environmental risk factors. Lancet 366: 1784-1793.

6. World Health Organization (2007) WHO calls for prevention of cancer through healthy workplaces. Press release.

7. Occupational Cancer (2007) United States National Institute for Occupational Safety and Health.

8. Jemal A, Siegel R, Ward E, Hao Y, Xu J, et al. (2008) Cancer statistics, 2008 CA Cancer J Clin 58: 71-96.

9. Macaluso M, Paggi MG, Giordano A (2003) Genetic and epigenetic alterations as hallmarks of the intricate road to cancer. Oncogene 22: 6472-6478.

10. Ericsson AC, Myles M, Davis W, Ma L, Lewis M, et al. (2010) Noninvasive detection of inflammation-associated colon cancer in a mouse model. Neoplasia 12: 1054-1065.

11. Santos RC, Rico MA, Bartrons R, Pujol FV, Rosa JL, et al. (2010) The Transcriptional Activation of the Cyclooxygenase-2 Gene in Zymosan-Activated Macrophages is Dependent on NF-Kappa B, C/EBP, AP-1, and CRE Sites. Inflammation [Epub ahead of print].

12. Lewis KN, Mele J, Hayes JD, Buffenstein R (2010) Nrf2, a Guardian of Healthspan and Gatekeeper of Species Longevity. Integr Comp Biol 50: 829843.

13. Falck E, Karlsson S, Carlsson J, Helenius G, Karlsson M, et al. (2010) Loss of Glutathione peroxidase 3 expression is correlated with epigenetic mechanisms in endometrial adenocarcinoma. Cancer Cell Int 10: 46.

14. Decicco-Skinner KL, Trovato EL, Simmons JK, Lepage PK, Wiest JS (2011) Loss of tumor progression locus 2 (tpl2) enhances tumorigenesis and inflammation in two-stage skin carcinogenesis. Oncogene 30: 389-397.

15. Lee KE, Bar-Sagi D (2010) Oncogenic KRas suppresses inflammationassociated senescence of pancreatic ductal cells. Cancer Cell 18: 448-458.

16. Gasche JA, Hoffmann J, Boland CR, Goel A (2010) Interleukin-6 promotes tumorigenesis by altering DNA methylation in oral cancer cells. Int $\mathrm{J}$ Cancer [Epub ahead of print].

17. Harris RE (2007) Cyclooxygenase-2 (cox-2) and the inflammogenesis of cancer. Subcell Biochem 42: 93-126.

18. Miura $Y$, Endo $T$ (2010) Survival responses to oxidative stress and aging Geriatr Gerontol Int 10 Suppl 1: S1-9.

19. Hussain SP, Harris CC (2007) Inflammation and cancer: an ancient link with novel potentials. Int J Cancer 121: 2373-2380.

20. Smart DK, Ortiz KL, Mattson D, Bradbury CM, Bisht KS, et al. (2004) Thioredoxin reductase as a potential molecular target for anticancer agents that induce oxidative stress. Cancer Res 64: 6716-6724.

21. Trachootham D, Alexandre J, Huang P (2009) Targeting cancer cells by ROS mediated mechanisms: a radical therapeutic approach? Nat Rev Drug Discov 8: 579- 591 
Citation: Singh RK, Sudhakar A, Lokeshwar BL (2011) From Normal Cells to Malignancy: Distinct Role of Pro-inflammatory Factors and Cellular Redox Mechanisms. J Cancer Sci Ther 3: 070-075. doi:10.4172/1948-5956.1000061

22. Schetter AJ, Heegaard NH, Harris CC (2010) Inflammation and cancer: interweaving microRNA, free radical, cytokine and p53 pathways. Carcinogenesis 31: $37-49$.

23. Hussain SP, Hofseth LJ, Harris CC (2003) Radical causes of cancer. Nat Rev Cancer 3: 276-285

24. Hofseth LJ, Saito S, Hussain SP, Espey MG, Miranda KM, et al. (2003) Nitric oxide-induced cellular stress and p53 activation in chronic inflammation. Proc Natl Acad Sci USA 100: 143-148.

25. Valko M, Rhodes CJ, Moncol J, Izakovic M, Mazur M (2006) Free radicals, metals and antioxidants in oxidative stress-induced cancer. Chem Biol Interact 160: $1-40$.

26. Conti A, Gulì C, Torre D, Tomasello C, Angileri F, et al. (2010) Role of Inflammation and Oxidative Stress Mediators in Gliomas. Cancers 2: 693-712.

27. Itzkowitz SH, Yio X (2004) Inflammation and cancer IV. Colorectal cancer in inflammatory bowel disease: the role of inflammation. Am J Physiol Gastrointest Liver Physiol 287: G7-17.

28. Pacher P, Beckman JS, Liaudet $L$ (2007) Nitric oxide and peroxynitrite in health and disease. Physiol Rev 87: 315-424

29. Koka PS, Mondal D, Schultz M, Abdel-Mageed AB, Agrawal KC (2010) Studies on molecular mechanisms of growth inhibitory effects of thymoquinone against prostate cancer cells: role of reactive oxygen species. Exp Biol Med (Maywood) 235: 751-760.

30. Bataller M, Portugal $\mathrm{J}$ (2005) Apoptosis and cell recovery in response to oxidative stress in p53-deficient prostate carcinoma cells. Arch Biochem Biophys 437: 151-158.

31. Chaiswing L, Oberley TD (2010) Extracellular/microenvironmental redox state. Antioxid Redox Signal 13: 449-465.

32. Rezvani HR, Rossignol R, Ali N, Benard G, Tang X, et al. (2010) XPC silencing in normal human keratinocytes triggers metabolic alterations through NOX1 activation-mediated reactive oxygen species. Biochim Biophys Acta [Epub ahead of print].

33. Muntané J, la Mata MD (2010) Nitric oxide and cancer. World J Hepatol 2 337-344.

34. Maynard S, Schurman SH, Harboe C, de Souza-Pinto NC, Bohr VA (2009) Base excision repair of oxidative DNA damage and association with cancer and aging. Carcinogenesis 30: 2-10.

35. Khoronenkova SV, Dianova II, Parsons JL, Dianov GL (2010) USP7/HAUSP stimulates repair of oxidative DNA lesions. Nucleic Acids Res [Epub ahead of print].

36. Hold GL, El-Omar EM (2008) Genetic aspects of inflammation and cancer Biochem J 410: 225-235.

37. Yuan Y, Zhang A, Huang S, Ding G, Chen R (2011) A PPAR \{gamma\} agonist inhibits aldosterone-induced mesangial cell proliferation by blocking ROSdependent EGFR intracellular signaling. Am J Physiol Renal Physiol 300: F393-402.

38. Zanotto-Filho A, Delgado-Cañedo A, Schröder R, Becker M, Klamt F, et al (2010) The pharmacological NFkappaB inhibitors BAY117082 and MG132 induce cell arrest and apoptosis in leukemia cells through ROS-mitochondria pathway activation. Cancer Lett 288: 192-203.

39. Juliette Martin, Dufour J (2008) Tumor suppressor and hepatocellular carcinoma. World J Gastroenterol 14: 1720-1733.

40. Kim KH, Park JY, Jung HJ, Kwon HJ (2011) Identification and biological activities of a new antiangiogenic small molecule that suppresses mitochondrial reactive oxygen species. Biochem Biophys Res Commun 404: 541-545.

41. Yoon JH, Lim TG, Lee KM, Jeon AJ, Kim SY, et al. (2011) Tangeretin Reduces Ultraviolet B (UVB)-Induced Cyclooxygenase-2 Expression in Mouse Epidermal Cells by Blocking Mitogen-Activated Protein Kinase (MAPK) Activation and Reactive Oxygen Species (ROS) Generation. J Agric Food Chem 59: 222-228.

42. Demaria S, Pikarsky E, Karin M, Coussens LM, Chen YC, et al. (2010) Cancer and inflammation: promise for biologic therapy. J Immunother 33: 335-351.
43. Mantovani A, Garlanda C, Allavena P (2010) Molecular pathways and targets in cancer-related inflammation. Ann Med 42: 161-170.

44. Oguma K, Oshima H, Oshima M (2010) Inflammation, tumor necrosis factor and Wnt promotion in gastric cancer development. Future Oncol 6: 515-26.

45. Boccardo E, Lepique AP, Villa LL (2010) The role of inflammation in HPV carcinogenesis. Carcinogenesis. 31: 1905-1912.

46. Verma V, Shen D, Sieving PC, Chan CC (2008) The role of infectious agents in the etiology of ocular adnexal neoplasia. Surv Ophthalmol 53: 312-331.

47. Gui-Zhong L, Libo M, Guanglin H, Jianwei W (2010) The correlation of extent and grade of inflammation with serum PSA levels in patients with IV prostatitis. Int Urol Nephrol [Epub ahead of print]

48. Singh RK, Lokeshwar BL (2009) Depletion of intrinsic expression of Interleukin-8 in prostate cancer cells causes cell cycle arrest, spontaneous apoptosis and increases the efficacy of chemotherapeutic drugs. Mol Cancer 8: 57

49. Araki S, Omori Y, Lyn D, Singh RK, Meinbach DM, et al. (2007) Interleukin-8 is a molecular determinant of androgen independence and progression in prostate cancer. Cancer Res 67: 6854-6862.

50. Ara T, Declerck YA (2010) Interleukin-6 in bone metastasis and cancer progression. Eur J Cancer 46: 1223-1231.

51. Haddad JJ (2002) Oxygen-sensing mechanisms and the regulation of redoxresponsive transcription factors in development and pathophysiology. Respir Res 3: 26.

52. Powell DW, Adegboyega PA, Di Mari JF, Mifflin RC (2005) Epithelial cells and their neighbors I. Role of intestinal myofibroblasts in development, repair, and cancer. Am J Physiol Gastrointest Liver Physiol 289: G2-7.

53. Bertucci F, Finetti P, Rougemont J, Charafe-Jauffret E, Cervera N, et al. (2005) Gene expression profiling identifies molecular subtypes of inflammatory breast cancer. Cancer Res 65: 2170-2178.

54. Guarino M, Tosoni A, Nebuloni M (2009) Direct contribution of epithelium to organ fibrosis: epithelial-mesenchymal transition. Hum Pathol 40: 1365-1376.

55. Li L, Steinauer KK, Dirks AJ, Husbeck B, Gibbs I, et al. (2003) Radiationinduced cyclooxygenase 2 up-regulation is dependent on redox status in prostate cancer cells. Radiat Res 160: 617-621.

56. Tang D, Loze MT, Zeh HJ, Kang R (2010) The redox protein HMGB1 regulates cell death and survival in cancer treatment. Autophagy 6: 1181-1183.

57. Zheng C, Yin Q, Wu H (2010) Structural studies of NF-kB signaling. Cell Res 21: 183-195.

58. Singh S, Srivastava SK, Bhardwaj A, Owen LB, Singh AP (2010) CXCL12 CXCR4 signaling axis confers gemcitabine resistance to pancreatic cancer cells: a novel target for therapy. Br J Cancer 103: 1671-1679.

59. Waugh DJ, Wilson C (2008) The interleukin-8 pathway in cancer. Clin Cancer Res 14: 6735-6741.

60. MacManus CF, Pettigrew J, Seaton A, Wilson C, Maxwell PJ, et al. (2007) Interleukin-8 signaling promotes translational regulation of cyclin D in androgenindependent prostate cancer cells. Mol Cancer Res 5: 737-748.

61. Haddad JJ (2004) Oxygen sensing and oxidant/redox-related pathways Biochem Biophys Res Commun 316: 969-977.

62. Liu H, Dinkova-Kostova AT, Talalay P (2008) Coordinate regulation of enzyme markers for inflammation and for protection against oxidants and electrophiles. Proc Natl Acad Sci USA 105: 15926-15931.

63. Haddad JJ (2002) Oxygen-sensitive pro-inflammatory cytokines, apoptosis signaling and redox-responsive transcription factors in development and pathophysiology. Cytokines Cell Mol Ther. 7: 1-14.

64. Nadiminty N, Lou W, Sun M, Chen J, Yue J, et al. (2010) Aberrant activation of the androgen receptor by NF-kappaB2/p52 in prostate cancer cells. Cancer Res 70: 3309-3319.

65. Singh S, Nannuru KC, Sadanandam A, Varney ML, Singh RK (2009) CXCR1 and CXCR2 enhances human melanoma tumourigenesis, growth and invasion. Br J Cancer 100: 1638-1646. 
Citation: Singh RK, Sudhakar A, Lokeshwar BL (2011) From Normal Cells to Malignancy: Distinct Role of Pro-inflammatory Factors and Cellular Redox Mechanisms. J Cancer Sci Ther 3: 070-075. doi:10.4172/1948-5956.1000061

66. Singh K, Lokeshwar B (2011) The IL-8 regulated chemokine receptor CXCR7 stimulates EGFR signaling to promote prostate cancer growth. Cancer Res (In Press)

67. Bartel DP (2009) MicroRNAs: target recognition and regulatory functions. Cell 136: $215-233$.

68. Bentwich I, Avniel A, Karov Y, Aharonov R, Gilad S, et al. (2005) Identification of hundreds of conserved and nonconserved human microRNAs. Nat Genet 37: $766-770$

69. Giannakakis A, Coukos G, Hatzigeorgiou A, Sandaltzopoulos R, Zhang L (2007) miRNA genetic alterations in human cancers. Expert Opin Biol Ther 7: 1375-1386.

70. Aqeilan RI, Calin GA, Croce CM (2010) miR-15a and miR-16-1 in cancer: discovery, function and future perspectives. Cell Death Differ 17: 215-220.

71. Cimmino A, Calin GA, Fabbri M, lorio MV, Ferracin M, et al. (2005) miR-15 and miR-16 induce apoptosis by targeting BCL2. Proc Natl Acad Sci USA 102: 13944-13949.

72. Oglesby IK, McElvaney NG, Greene CM (2010) MicroRNAs in inflammatory lung disease--master regulators or target practice? Respir Res11: 148.
73. Meng F, Henson R, Wehbe-Janek H, Smith H, Ueno Y, et al. (2007) The MicroRNA let-7a modulates interleukin-6-dependent STAT-3 survival signaling in malignant human cholangiocytes. J Biol Chem 282: 8256-8264.

74. Li T, Morgan MJ, Choksi S, Zhang Y, Kim YS, et al. (2010) MicroRNAs modulate the noncanonical transcription factor NF-kappaB pathway by regulating expression of the kinase IKKalpha during macrophage differentiation. Nat Immunol 11: 799-805.

75. Pan X, Wang ZX, Wang R (2011) MicroRNA-21: a novel therapeutic target in human cancer. Cancer Biol Ther 10: 1224-1232.

76. Asangani IA, Rasheed SA, Nikolova DA, Leupold JH, Colburn NH (2008) MicroRNA-21 (miR-21) post-transcriptionally downregulates tumor suppressor Pdcd4 and stimulates invasion, intravasation and metastasis in colorectal cancer. Oncogene 27: 2128-2136.

77. Iliopoulos D, Jaeger SA, Hirsch HA, Bulyk ML, Struhl K (2010) STAT3 activation of miR-21 and miR-181b-1 via PTEN and CYLD are part of the epigenetic switch linking inflammation to cancer. Mol Cell 39: 493-506.

78. Seike M, Goto A, Okano T, Bowman ED, Schetter AJ, et al. (2009) MiR-21 is an EGFR-regulated anti-apoptotic factor in lung cancer in never-smokers. Proc Natl Acad Sci U S A 106: 12085-12090. 